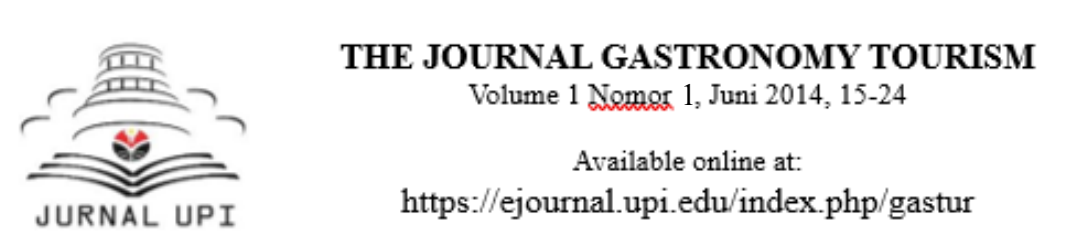

\title{
PENGARUH SALURAN DISTRIBUSI DAN BIAYA PROMOSI TERHADAP VOLUME PENJUALAN DI RESTORAN MCDONALD SE-KOTA BOGOR
}

\author{
Astrid Ilmina, Dewi Turgarini, Ani Pinayani \\ Program Studi Manjemen Industri Katering \\ Fakultas Pendidikan Ilmu Pengetahuan Sosial \\ Universitas Pendidikan Indonesia \\ e-mail : astrid_ilmina@ymail.com
}

\begin{abstract}
McDonald restaurant is tha franchise restaurant and have American restaurant theme. The restaurant have currently competition very hard. McDonald restaurant in the city of Bogor add have reference with the factual of fact and extact to determinate sales volume the restaurant. Based on research result obtained that distribution channel with dimension delivery service, drive thru, and eat-in, along with promotion cost, has positive and significant impactin a simultaneously. But in a partially, a distribution channel with dimension eat-in with promotion cost, have a positive but not significant to sales volume at McDonald Restaurant in Bogor city.

Keyword : sales volume, McDonald Restaurant in Bogor City.
\end{abstract}

\begin{abstract}
Abstrak
Restoran McDonald merupakan restoran waralaba yang bertemakan American Restoran. Di tengah persaingan yang cukup ketat, restoran McDonald se-kota Bogor akan menambah referensi dengan fakta yang faktual dan akurat dalam menentukan volume penjualan terhadap restoran. Berdasarkan dari hasil penelitian yang dapat di peroleh, bahwa saluran distribusi dengan dimensi delivery service, drive thru, dan eat-in, serta biaya promosi memiliki pengaruh positif secara keseluruhan, namun secara parsial, saluran distribusi dengan dimensi eat-in serta biaya promosi memiliki pengaruh positif namun tidak signifikan terhadap volume penjualan di restoran McDonald se-kota Bogor.

Kata kunci : Volume Penjualan, restoran McDonald se-kota Bogor.

\section{PENDAHULUAN}

Restoran McDonald ialah salah satu restoran cepat saji terbesar di dunia, yang memiliki hak waralaba. Restoran ini memiliki konsep A'la Carte restoran dan Table D'hote restoran. Restoran McDonald dibangun atas dasar pemikiran QSC dan V,yaitu quality, service, cleanliness dan value yang menjadi landasan restoran.

Kota Bogor merupakan salah satu kota yang memiliki persaingan sangat kuat dalam segi kuliner, secara otomatis makan akan menambah referensi dalam meningkatkan volume penjualan terhadap restora. Berikut ini adalah daftar nama cabang restoran McDonald yang berada di daerah kota Bogor :
\end{abstract}


Tabel 1

Daftar Nama Restoran McDonald se-kota Bogor

\begin{tabular}{|l|l|l|}
\hline No & \multicolumn{1}{|c|}{$\begin{array}{c}\text { Cabang } \\
\text { Restoran }\end{array}$} & \multicolumn{1}{|c|}{ Lokasi } \\
\hline 1 & McD Lodaya & $\begin{array}{l}\text { J1. Raya Pajajaran } \\
\text { no.21 }\end{array}$ \\
\hline 2 & McD Plasa Indah & $\begin{array}{l}\text { Jl.KH.Sholeh } \\
\text { Iskandar no.10 }\end{array}$ \\
\hline 3 & $\begin{array}{l}\text { McD Hero } \\
\text { Pajajaran }\end{array}$ & Jl.Pajajaran no.24 \\
\hline 4 & $\begin{array}{l}\text { McD Sukahati } \\
\text { Cibinong }\end{array}$ & $\begin{array}{l}\text { Jl.Raya Cibinong } \\
\text { no.13 }\end{array}$ \\
\hline
\end{tabular}

Sumber :LSM (local store marketing) McDonald se-kota Bogor

Data pada tabel 1 menunjukan bahwa terdapat empat cabang restoran McDonald yang berada di daerah kota Bogor. Dan pada saat ini, seluruh cabang restoran McDonald yang berada di kota Bogor mengalami jumlah pembeli dan penjualan yang fluktuatif Seperti yang terlihat, tabel jumlah pembeli dan penjualan, seluruh cabang restoran McDonald se-kota Bogor pada periode tahun 2011, sebagai berikut :

\section{Tabel 2}

Data Jumlah Pembeli dan Penjual Restoran McDonald se-kota Bogor tahun 2011

\begin{tabular}{|c|c|c|c|c|c|}
\hline $\mathrm{N}$ & Bulan & $\begin{array}{c}\text { Jumla } \\
\mathrm{h} \\
\text { Pemb } \\
\text { eli } \\
(\text { oran } \\
\mathrm{g})\end{array}$ & $\begin{array}{c}\text { Kenaika } \\
\mathrm{n} / \\
\text { Penurun } \\
\text { an } \\
(\%)\end{array}$ & $\begin{array}{c}\text { Volume } \\
\text { Penjual } \\
\text { an } \\
\text { dalam } \\
\text { rupiah } \\
(000)\end{array}$ & $\begin{array}{c}\text { Kenaik } \\
\text { an/ } \\
\text { Penuru } \\
\text { nan } \\
(\%)\end{array}$ \\
\hline 1 & Januari & $\begin{array}{c}1355 \\
35\end{array}$ & 0 & $\begin{array}{c}308225 \\
6\end{array}$ & 0 \\
\hline 2 & $\begin{array}{c}\text { Februar } \\
\text { i }\end{array}$ & $\begin{array}{c}1190 \\
23\end{array}$ & -6.48 & $\begin{array}{c}278030 \\
5\end{array}$ & -5.15 \\
\hline 3 & Maret & $\begin{array}{c}1165 \\
71\end{array}$ & -1.04 & $\begin{array}{c}256540 \\
3\end{array}$ & -4.01 \\
\hline 4 & April & $\begin{array}{c}1127 \\
29\end{array}$ & -1.67 & $\begin{array}{c}288764 \\
4\end{array}$ & 5.90 \\
\hline 5 & Mei & $\begin{array}{c}1368 \\
33\end{array}$ & 9.65 & 341286 & 8.33 \\
& & 4 & \\
\hline 6 & Juni & $\begin{array}{c}1401 \\
52\end{array}$ & 1.19 & 337296 & -0.58 \\
\hline 7 & Juli & $\begin{array}{c}1243 \\
56\end{array}$ & -5.97 & 313684 & -3.62 \\
\hline
\end{tabular}




\begin{tabular}{|c|c|c|c|c|c|}
\hline 8 & $\begin{array}{c}\text { Agustu } \\
\text { s }\end{array}$ & $\begin{array}{c}1442 \\
31\end{array}$ & 7.39 & 359107 & 6.75 \\
1 & \\
\hline 9 & $\begin{array}{c}\text { Septem } \\
\text { ber }\end{array}$ & $\begin{array}{c}1646 \\
92\end{array}$ & 6.62 & $\begin{array}{c}408574 \\
6\end{array}$ & 6.44 \\
\hline 10 & $\begin{array}{c}\text { Oktobe } \\
\text { r }\end{array}$ & $\begin{array}{c}1400 \\
24\end{array}$ & -8.09 & $\begin{array}{c}342385 \\
9\end{array}$ & -8.81 \\
\hline 11 & $\begin{array}{c}\text { Novem } \\
\text { ber }\end{array}$ & $\begin{array}{c}1270 \\
73\end{array}$ & -4.84 & 331692 & -1.58 \\
& & 5 & \\
\hline 12 & $\begin{array}{c}\text { Desem } \\
\text { ber }\end{array}$ & $\begin{array}{c}1130 \\
33\end{array}$ & -5.84 & $\begin{array}{c}322879 \\
9\end{array}$ & -1.35 \\
\hline
\end{tabular}

Sumber : data pra penelitian pada Restoran McDonald se-Kota Bogor

Data pada tabel 2 diatas, dapat menggambarkan bahwa jumlah pembelian dan penjualan di di seluruh restoran McDonald se-kota Bogor tahun 2011 mengalami kenaikan dan penuruan yang fluktuatif. Terdapat penurunan sebanyak delapan kali dalam satu tahun terakhir pada jumlah pembeli dan jumlah penjualan. Tingkat penurunan terbesar jumlah pembeli dan jumlah penjualan terjadi pada bulan oktober yaitu penurunan total pembeli sebesar $-8,09 \%$ dan total penjualan sebesar $-8,81 \%$.

Menurut Cummins (2009:123), "Volume penjualan dalam suatu produk dalam jangka panjang akan tergantung pada serangkaian faktor pemasaran yang paling mendasar, seperti mutu, harga, distribusi, dan promosi.". Jadi dengan demikian, volume penjualan dalam suatu perusahaan sangat dipengaruhi oleh faktor-faktor pemasaran yaitu mutu, harga, distribusi dan promosi. Untuk memastikan ulang, penulis melakukan rekapitulasi data pra penelitian yang didapat dengan cara penyebaran kuesioner terhadap 30 responden yaitu para karyawan di restoran McDonald se-kota Bogor.

Tabel 3

Tabel Indikator yang Mempengaruhi Volume Penjualan di Restoran McDonald se-kota Bogor periode 2011

\begin{tabular}{|c|c|c|}
\hline KETERANGAN & FREKUENSI & $\begin{array}{c}\text { PRESENTASE } \\
(\%)\end{array}$ \\
\hline Variasi produk & 22 & 77.33 \\
\hline Kualitas produk & 25 & 83.33 \\
\hline $\begin{array}{c}\text { Kualitas } \\
\text { pelayanan }\end{array}$ & 23 & 76.66 \\
\hline $\begin{array}{c}\text { Saluran } \\
\text { Distribusi }\end{array}$ & 20 & 66.66 \\
\hline Lokasi & 22 & 77.33 \\
\hline Biaya Promosi & 21 & 70 \\
\hline Harga & 23 & 76.66 \\
\hline
\end{tabular}

Sumber : Pengolahan data pra survei 2011

Menanggapi dari hasil data pra survei pada tabel diatas, faktor-faktor yang diduga kurang mempengaruhi volume penjualan dan yang menjadi pertimbangan para karyawan di restoran McDonald se-kota Bogor ialah saluran distribusi yang 
persentasenya mencapai $66,66 \%$, serta biaya promosi sebanyak $70 \%$. Dari uraian diatas maka peneliti tertarik untuk meneliti judul bahasan :

"Pengaruh Saluran Distribusi dan Biaya Promosi terhadap Volume Penjualan di Restoran McDonald se-kota Bogor”

\section{METODE PENELITIAN}

Metode penelitian yang digunakan oleh penulis ialah metode penelitian deskriptif analisis, yaitu suatu metode dalam meneliti status sekelompok manusia, suatu objek, suatu set, kondisi, suatu sistem pemikiran ataupun kelas peristiwa pada masa sekarang (Riduwan dan Sunarto, 2003;52).

Metode pengumpulan data yang digunakan ialah data sekunder dengan memperoleh dari pihak perusahaan, wawancara, dokumentasi dan observasi.

\section{Operasionalisasi Variabel}

\section{A. Volume Penjualan}

Volume penjualan merupakan suatu studi mendalam tentang masalah-masalah penjualan bersih dari laporan rugi laba perusahaan.

(Basu

Swastha,2008:141)

Faktor-faktor yang mempengaruhi volume penjualan, yaitu ;

1. Produk yaitu barang yang diperjualbelikan.

2. Harga, yang merupakan salah satu poin yang penting dalam memasarkan produk, harga adalah penentu atau patokan produk yang dipasarkan.

3. Saluran distribusi, yaitu saluran yang digunakan perusahaan untuk memasarkan produk.

4. Promosi penjualan atas produk yitu memasarkan produk dengan berbagai alat perusahaan dengan biaya promosi yang sudah ditentukan untuk menarik perhatian pelanggan.

5. Organisasi penjualan yaitu suatu hal yang terpenting dalam proses penjualan agar penjualan dapat terarah dan teratur.

6. Selera konsumen ialah keinginan dan harapan para konsumen yang berbeda.

7. Persaingan ialah perlawanan di beberapa perusahaan yang menawarkan produkproduk yang sama.

8. Perekonomian dan kebijakan pemerintah.

B. Saluran Distribusi

Saluran distribusi adalah rute atau rangkaian perantara, baik yang dikelola pemasaran maupun independen, dalam menyampaikan barang dari produsen ke konsumen (Fandy Tjiptono, 2008:187).

Variasi saluran distribusi jasa,yaitu:

1. Penyedia jasa $\rightarrow$ pelanggan

Sering disebut penjualan langsun, misalnya jasa konsultasi, akuntansi, dan manajemen.

2. Penyedian jasa $\rightarrow$ agen/bloker $\rightarrow$ pelanggan

Misalnya, bloker asuransi, agen perumahan, agen pengiriman paket (courierservice), dan agen perjalanan.

3. Penyedia jasa $\rightarrow$ agen penjual $\rightarrow$ agen pembeli pelanggan

Misalnya $>$ pialang saham, dan pemilik saham yang menjual sahamnya. 
4. Penyedia jasa $\rightarrow$ waralaba $\rightarrow$ pelanggan

Misalnya, fast food, service mobil, dan dry cleaning.

Saluran distribusi restoran McDonald se-kota Bogor terbagi atas tiga jenis saluran, diantaranya:

- Delivery service

- Drive thru

- Eat-in

\section{Biaya Promosi}

Biaya promosi adalah sejumlah dana yang dikucurkan perusahaan ke dalam promosi untuk meningkatkan penjualan perusahaan.(Sinamora, 2002:702).

Jenis biaya promosi (Kotler, 2002:112), diantaranya:

- Biaya iklan

- Biaya promosi penjualan

- Biaya hubungan masyarakat

- Biaya penjualan personal

\section{Teknik Analisis Data}

Pada penelitian ini, terdapat empat variabel independen yaitu dimensi dari saluran distribusi pada restoran McDonald, diantaranya variabel delivery service, drive thru, eat-in, serta variabel biaya promosi.

Metode yang digunakan ialah metode regresi linear berganda dengan menggunakan uji asumsi klasik yaitu pengujian asumsi agar model yang terbentuk memberikan estimasi BLUE (best linier unbashied estimator) yakni tidak adanya heteroskedastistian, normalitas, autokorelasi dan multikolinieritas, koefisien determinasi, serta pengujian hipotesis secara parsial dan simultan, dan pengolahan data menggunakan bantuan SPSS 18 for windows.

Dalam penelitian ini, data yang diteliti ialah jenis data panel yaitu penggabungan data crossection dan data times series, dengan populasi penelitian ialah empat restoran cabang McDonald yang berada di wilayah kota Bogor dan sampel sebanyak 144 bulan. Instrumen data didapat dari saluran distribusi dengan dimensi delivery service, drive thru, eat-in, serta biaya promosi selama tiga tahun yaitu pada tahun 2009 sampai 2011. Dengan teknik sampling nonpropability sampling yaitu teknik sampling yang tidak memberikan peluang bagi setiap unsur populasi yang dipilih sebagai anggota sampel.

\section{HASIL PEMBAHASAN}

Restoran McDonald hadir di Indonesia tahun 1991 yang merupakan negara ke 70 dari McDonald dari seluruh dunia. H.Bambang Rachmadi Msc.Mba adalah warga negara Indonesia pertama yang berhasil mendapatkan hak master franchise dari McDonald Coorporation yang mengalahkan 13.000 pesaing. Restoran McDonald pertama di Jakarta ialah McDonald Sarinah, tepat tanggal 22 Febuari 1991 restoran ini beroprasi dengan mempekerjakan 460 crew dan 26 manajer.

Restoran McDonald baik internasional maupun nasional mempunyai visi yang sama ialah "To be the world's best quick service restaurant experience" yaitu menjadi restoran cepat saji yang paling berpengalaman, paling cepat melayani dan 
terbaik di seluruh dunia dan misi dari restoran McDonald ialah memahami misi kami dan bagaimana menjadikannya menjadi kenyataan pada restoran McDonald.

Perkembangan McDonald dalam saat ini hampir 200 restoran cabang seIndonesia dengan jumlah seluruh pegawai sekitar 8000 orang. McDonald selalu berpegang teguh pada pada filosofi QSC dan V, yaitu quality, service, cleanliness, dan value. McDonald Indonesia menerapkan sistem mutakhir HACCP (hazard analysis critical control point) atau dalam bahasa Indonesia disebut Analisis titik bahaya kondisi kritis dan sertifikasi halal dari LPPOM MUI sejak tahun 1994. Tahun 2009, restoran McDonald seluruh Indonesia resmi diambil oleh PT Rekso Nasional Food dari PT Biana Nusa Rama, PT Rekso Nasional Food adalah anak perusahaan Rekso Group, Induk usaha PT Sari Sosro produsen teh sosro.

Restoran McDonald menerapkan prinsip waralaba (franchising) ialah suatu prinsip yang hubungannya terus-menerus diamana seorang pemilik waralaba, memberikan kepada seorang penyewa waralaba hak bisnis, untuk mengoprasikan atau menjual suatu produk. Bentuk dari waralaba yang digunakan McDonald ialah waralaba format bisnis (bussines format franchising), yaitu suatu hubungan bisnis terus menerus antara pemilik dan penyewa waralaba. Biaya waralaba pada satu periode, pada umumnya berkisar $3-7 \%$ dari penerimaan modal awal.

Restoran McDonald ialah salah satu restoran fast food terbesar di dunia, maka selain promosi, saluran distribusi yang dilakukan terbagi menjadi dua bagian saluran, yaitu saluran distribusi langsung diantaranya drive thru dan eat-in, dan saluran distribusi tidak langsung yaitu delivery service, dengan menggunakan jasa pengantar.

Cara ini dilakukan agar memudahkan para konsumen untuk mendapatkan produk-produk yang ditawarkan di restoran McDonald dan diharapkan dengan cara ini akan meningkatkan volume penjualan pada restoran.

Restoran McDonald se-kota Bogor, hanya terdapat empat cabang. Maka dari itu populasi hanya terdapat empat restoran saja, dapat dilihat pada tabel di bawah ini :

Tabel 4

Populasi dan Sampel

\begin{tabular}{|l|l|c|}
\hline No & Populasi restoran & $\begin{array}{l}\text { Sampel } \\
\text { (Bulan) }\end{array}$ \\
\hline 1 & McD Lodaya & 36 \\
\hline 2 & McD Plasa Indah & 36 \\
\hline 3 & McD Hero Pajajaran & 36 \\
\hline 4 & $\begin{array}{l}\text { McD Sukahati } \\
\text { Cibinong }\end{array}$ & 36 \\
\hline \multicolumn{2}{|c|}{ Total Sampel } & 144 \\
\hline
\end{tabular}

Sumber: data dari LSM (local store marketing) McDonald se-kota Bogor

Pada tabel 4, menunjukan bahwa populasi restoran hanya terdapat empat cabang restoran McDonald se-kota Bogor, dengan total sampel sebanyak 144 bulan.

Dalam uji normalitas nilai sig > 0,05 dapat dilihat dari hasil kolomorgrovsmirnov sebesar 0,531 dan nilai sig=0,941, maka Hasil uji normalitas disimpulkan bahwa saluran distribusi dalam bentuk delivery service, drive thru, eat-in dan biaya promosi sebagai variabel dependen berdistribusi normal terhadap volume penjualan. 
Dalam uji autokorelasi dilakukan dengan menggunakan Durbin-Watson (D$\mathrm{W})$, dengan tingkat kepercayaan $=5 \%$, apabila $(\mathrm{D}-\mathrm{W})$ terletak -2 sampai +2 maka tidak ada autokorelasi, diperoleh nilai $\mathrm{d}=1,884, \mathrm{~d}_{\mathrm{L}}=1,592$ dan $\mathrm{d}_{\mathrm{U}}=1,758$ dikarenakan $\mathrm{d}_{\mathrm{U}}<\mathrm{d}<4-\mathrm{d}_{\mathrm{U}}$, dapat dilihat pada gambar di bawah ini :

\section{Gambar 1}

Model Uji Autokolerasi

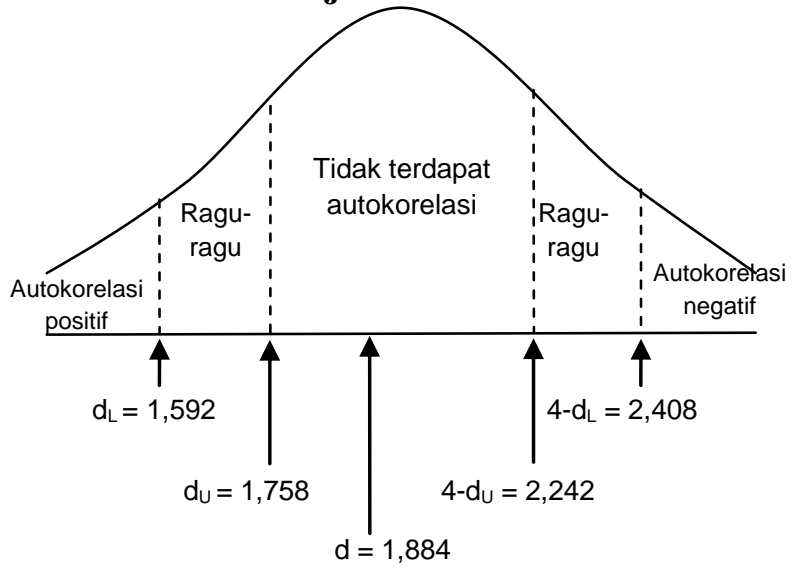

Pada gambar 1 maka, dapat disimpulkan bahwa saluran distribusi dalam bentuk delivery service, drive thru, eat-in dan biaya promosi sebagai variabel dependen tidak adanya autokorelasi terhadap volume penjualan.

Uji heteroskedastistias dapat disimpulkan variabel independen tidak ada hubungan dengan absolut residunya yang dapat dilihat dalam scattlerplot.

\section{Gambar 2}

\section{Hasil Uji Heterokedastisitas}

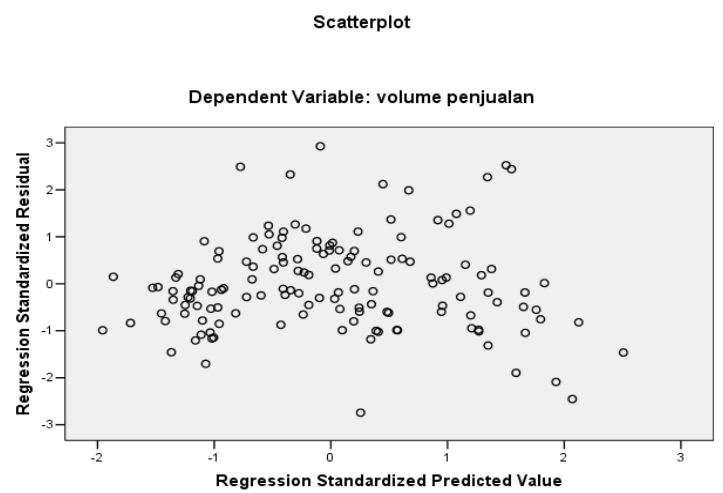

Dengan penyebaran titik yang tidak merata dan tidak membentuk suatu pola. Maka dapat diartikan tidak adanya heteroskedastistias pada saluran distribusi dalam bentuk delivery service, drive thru, eat-in dan biaya promosi terhadap volume penjualan. 
Pengujian selanjutnya ialah uji multikolinieritas, yaitu pengujian dilakukan agar dapat mengetahui adanya kolerasi antar variabel independen dan dependen, pengujian ini dapat dilihat dari nilai tolerance yang rendah sama dengan nilai VIF (variance inflation factor) yang tinggi dengan toleran 0,10 atau nilai VIF diatas 10.

\section{Tabel 5}

Hasil Uji Multikolinieritas

\begin{tabular}{|c|c|c|}
\hline \multirow[t]{2}{*}{ Model } & \multicolumn{2}{|c|}{$\begin{array}{l}\text { Collinierity } \\
\text { Statistics }\end{array}$} \\
\hline & Tolerance & VIF \\
\hline Mds & .853 & 1.173 \\
\hline & .759 & 1.317 \\
\hline eat-in & .952 & 1.050 \\
\hline bromosi biaya & .684 & 1.462 \\
\hline
\end{tabular}

a. dependent variabel: volume penjualan

Hasil penelitian pada tabel 6 dapat ditarik kesimpulan, dalam uji multikolinieritas, tidak terdapat multikolinieritas antara variabel independen yaitu saluran distribusi dengan dimensi delivery service, drive thru, eat-in dan biaya promosi terhadap volume penjualan.

Berdasarkan hasil perhitungan secara parsial dapat diperoleh adanya pengaruh yang signifikan antara variabel drive thru $\left(\mathrm{X}_{1.2}\right)$ dengan variabel volume penjualan $(\mathrm{Y})$, sebesar $28,11 \%$ dan variabel delivery service $\left(\mathrm{X}_{1.1}\right)$ dengan variabel volume penjualan (Y), sebesar 25,69\%, Hasil ini menunjukan bahwa delivery service dan drive thru berkontibusi positif dan cukup besar terhadap volume penjualan di restoran McDonald se-kota Bogor.

Secara parsial, variabel eat-in $\left(\mathrm{X}_{1.3}\right)$ tidak berpengaruh signifikan terhadap variabel volume penjualan $(\mathrm{Y})$, yaitu sebesar $2,20 \%$ dan variabel biaya promosi $\left(\mathrm{X}_{2}\right)$ tidak berpengaruh secara signifikan terhadap variabel volume penjualan (Y) sebesar $1,81 \%$. Hasil ini menunjukan bahwa variabel eat-in dan variabel biaya promosi memiliki kontribusi positif namun tidak signifikan terhadap variabel volume penjualan di restoran McDonald se-kota Bogor.

Berdasarkan hasil perhitungan secara simultan, dapat diperoleh adanya pengaruh secara positif dan signifikan antara variabel independen dan variabel dependen yaitu sebesar 57,8\%, dan sisanya 42,2\% merupakan faktor lain, dimana penulis tidak meneliti faktor tersebut. Menurut dugaan peneliti ada faktor lain yang mempengaruhi volume penjualan selain variabel yang diteliti diataranya harga (price), produk (product), layanan konsumen (customer service), karyawan (people), dan proses (process).

\section{KESIMPULAN}

Berdasarkan hasil analisis dan pengolahan data pada penelitian tentang pengaruh saluran distribusi dan biaya promosi terhadap volume penjualan di restoran McDonald se-kota Bogor, maka dapat disimpulkan sebagai berikut : 
1. Terdapat pengaruh positif dan signifikan antara variabel saluran distribusi dengan dimensi delivery service terhadap volume penjualan pada restoran McDonald sekota Bogor

2. Terdapat pengaruh positif dan signifikan antara variabel saluran distribusi dengan dimensi drive thru terhadap volume penjualan pada restoran McDonald se-kota Bogor

3. Terdapat pengaruh positif namun tidak signifikan antara variabel saluran distribusi dengan dimensi eat-in terhadap volume penjualan pada restoran McDonald se-kota Bogor

4. Terdapat pengaruh positif namun tidak signifikan antara variabel biaya promosi terhadap volume penjualan pada restoran McDonald se-kota Bogor

5. Terdapat pengaruh positif dan signifikan secara simultan antara variabel independen terhadap variabel dependen.

\section{DAFTAR PUSTAKA}

Alex, Nitisemito. (1991). Marketing, Cetakan kedelapan. Ghalia :Jakarta

Alma,B.(2002).Manajemen Pemasaran dan Pemasaran Jasa. Pustaka Setia Bandung

Bilson, Sinamora. (2002). Panduan Riset Prilaku Konsumen. Pustaka Utama : Surabaya

Basu,Swatha.et al. (2008). Manajemen Pemasaran Modern. Cetakan ke delapan. Liberty : Yogyakarta

Boediono. (1991). Ekonomi Mikro. Edisi Kedua. BFPE-UGM : Yogyakarta

Coorporate Information. (2009). Visi dan Misi [online:]. Tersedia : http://www.mcdonalds.co.id/about--us/coorporate-information/visi-dan-misi/ [ 15 Maret 2012]

D.W.Foster .(1985). Prisip-Prinsip Pemasaran. Erlangga : Jakarta

Euis. Ratna. Kumala.(2009). Teori Tentang Pariwisata. [online:]. Tersedia: http://www.blog.euisratnakomala.com/teori-tentang-pariwisata.html [15 Maret 2012]

Gudjarati, Damodar. (2003). Ekonomi Dasar . Erlangga : Jakarta

Gunawan. Sumodiningrat. (2001), Pengantar Ekonometrika. Edisi Pertama Cetakan Keenam. BPFE :Yogyakarta

H. Kodyat. (1983). Definisi Pariwisata. [online:]. Tersedia : Budianto, http://upi0704500.blogupi.edu/2010/01/09/atribut-produk-wisata-sebagai-

faktor-kepuasan-guna-meningkatkan-wisatawan-pada-tempat-wisata-taman-x [13 Januari 2012]

Harry. (1998). Mencegah Penurunan Volume Penjualan. [online]. Tersedia :JournalOnline,(2007), http://email.tailorednews.com/thusubscrip.net/viewcast. aspx. [13 Januari 2012]

Imam. Ghozali. (2011). Aplikasi Analisis Multivariate dengan Program SPSS. UNDIP : Semarang

Julian. Cummnis. (2009). Promosi Penjualan. Karisma : Jakarta

Komarudin, Sastradipoerna.(2003). Manajemen Marketing. Edisi Pertama. Kappa Sigma : Jakarta 
Kotler,Philip dan Amstrong, Gary. (1997). Dasar- dasar Pemasaran. Edisi Bahasa Indonesia jilid 1. Jakarta :Prenhalindo.

Kotler,Philip. (2002). Manajemen Pemasaran Edisi Milenium jilid 1. Prenhallindo : Jakarta

Levy and Weisz. (2004), Retailing Managemen. Boston Mc Graw : Hill. Irwin

Marsum. (2007). Restoran dan Segala Permasalahannya.Andi : Yogyakarta

Moh Nasir, ph.D. (2005). Metode Penelitian. Ghalia Indonesia : Jakarta

No. Name. (2009) Jurnal Uji Asumsi Klasik. [online:]. Tersedia : http://jurnalsdm.blogspot.com /2009/04/uji-asumsi-klasik-regresi-berganda.html. [ tanggal, 2 April 2012]

No. Wame. Wisata Bogor [online:] Tersedia : http://www.beritabogor.com/2011/01/visit-bogor-2011.html. [diunggah tanggal, 15 Maret 2012]

No.Name. (2010). Letak Geografis. [online:]. Tersedia : http://www.kotabogor.go.id/sekilas-bogor/letak-geografis. [tanggal, 15 Maret 2012]

No.Name. (1996). [online:]. Tersedia : http://Petra_university.ac.id. [tanggal, 25 juni 2012]

No.Name. (1995). [online:]. Tersedia : http://www.scrib.com. [tanggal, 25 juni 2012]

Pratama Raharja, dan Mandala Manurung. (2004). Ekonomi Makro. FEUI : Jakarta

Purwasuka. (2009), Teori Penjualan. [online:]. Tersedia : http://www. purwasuka. web.id/15/11/2009/ mengenai teori penjualan/ [tanggal, 15 Maret 2012]

Rambat. Lupiyoadi. (2006). Manajemen Pemasaran Jasa: Teori dan Praktek. Salemba : Jakarta

Ratih Huriyati. (2008). Bauran Pemasaran dan Loyalitas Konsumen. Alfabeta : Bandung

Richard Sihite. (2000). Definisi Pariwisata. [online:]. Tersedia :Heriyadi Rahmad, Error! Hyperlink reference not valid.. [tanggal, 13 Januari 2012]

Ridho. Onfire. (2010). Visi Misi Mc Donalds Dunia. [online:]. Tersedia : http://www.sumberbacaan.com/mengenai+visi+misi+mc+donalds+ridho+ onfire .html. [tanggal, 15 Maret 2012]

Riduwan. (2003). Rumus dan Data dalam Statistika. Alfabeta : Bandung

Santoso, Singgih. (2002). SPSS Mengolah Data Statistic Secara Profesional. Elex Media Komputindo :Jakarta

Sugiono. (2009). Metode Penelitian Kuantitatif dan Kualitatif. Penerbit CV.ALFABETA : Bandung

Syahrul, dan M.Ardi Nizar. (2000). Kamus Akuntansi. Citra Harta Prima :Jakarta

Tjiptono, Fandy . (2008) , Manajemen Pemasaran dan Jasa. Cetakan ke delapan Andi : Yogyakarta

Wikipedia.

(2011).

Sejarah

McDonald.

[online:].Tersedia:http://id.wikipedia.org/wiki/mcdonald

William, J Staton. (1991). Prinsip Pemasaran. Erlangga : Jakarta

Winardi. (1991). Pengantar Tentang Riset Pemasaran, Mandar Maju : Bandung

Wasis. (1992). Pengantar Ekonomi Perusahaan. Alumni : Bandung 